Journal of Bangladesh Academy of Sciences, Vol. 36, No. 2, 233-240, 2012

\title{
SUBSTRATE TEMPERATURE EFFECT ON THE STRUCTURAL AND OPTICAL PROPERTIES OF ZnSe THIN FILMS
}

\author{
M.R.A. BHUIYAN* ${ }^{*}$ M.A.H. MIAH AND J. BEGUM ${ }^{1}$ \\ Department of Applied Physics, Electronics and Communication Engineering, \\ Islamic University, Kushtia-7003, Bangladesh
}

\begin{abstract}
Zinc selenide (ZnSe) thin films were deposited on to chemically and ultrasonically cleaned glass substrates at different substrate temperatures from room temperature to $200^{\circ} \mathrm{C}$ keeping the thickness fixed at $300 \mathrm{~nm}$ by using thermal evaporation method in vacuum. The structural properties of the films were ascertained by X-ray diffraction (XRD) method utilizing a diffractometer. The optical properties were measured in the photon wavelength ranging between 300 and $2500 \mathrm{~nm}$ by using a UV-VIS-NIR spectrophotometer. The XRD patterns reveal that the films were polycrystalline in nature exhibiting f.c.c zincblende structure with average lattice parameter, $a=5.6873 \AA$. The grain size, strain and dislocation densities of the films have been calculated. The optical transmittance and reflectance were utilized to compute the absorption coefficient, band gap energy and refractive index of the films. The band gap energy of the films was extracted from the absorption spectra. The direct band gap energy of the films slightly increases with substrate temperature.
\end{abstract}

Key words: ZnSe thin films, Substrate temperature, Structural and optical properties

\section{INTRODUCTION}

The ZnSe, a wide band gap semiconductor has high potential for application in optoelectronic devices. Because of its large band gap, $\mathrm{ZnSe}$ has been used as window layer for the fabrication of photovoltaic solar cells. For high efficiency solar cells, a high band gap material is required for maximum transmission of solar spectrum, which increases the open circuit voltage of the solar cell. Since solar cell window material CdS having band gap of $2.4 \mathrm{eV}$, the blue region of solar spectrum, ZnSe having band gap between 2.799 and $2.803 \mathrm{eV}$ is an alternative to $\mathrm{CdS}$ material. Particularly, ZnSe is an interesting II-VI compound semiconducting material, widely used in optoelectronic devices, because its band gap energy belongs to the visible region (Huanyong and Wanqi 2003). Therefore, there is currently a major interest in $\mathrm{ZnSe}$ based materials suitable for the fabrication of light emitting devices operating in the blue-green region (Guha et al. 1992) and in the manufacture of optical components, mirrors, lenses etc. for IR lasers

*Corresponding author: <mrab_iu@yahoo.com>.

${ }^{1}$ Experimental Physics Division, Atomic Energy Centre, GPO Box 164, Dhaka-1000, Bangladesh. 
(Guozhen et al. 2003, Yi et al. 1994). A number of methodologies are employed in the formation of high quality $\mathrm{ZnSe}$ thin films, including such as chemical vapour deposition, MOCVD, electrodeposition, photochemical deposition, chemical bath deposition (CBD), pulsed laser deposition and thermal evaporation (Chaliha et al. 2008, Choudhury et al. 2004, Chu et al. 1992, Kale and Lokhande 2005, Kumaresan et al. 2002, Perna et al. 2002). However, thermal evaporation is extremely simple and viable compared to other cost intensive methods. Here effects of substrate temperature on the structural and optical properties of $\mathrm{ZnSe}$ thin films have been presented.

\section{MATERIALS AND METHODS}

The films of $\mathrm{ZnSe}$ were deposited on to cleaned glass substrates by thermal evaporation method in vacuum $\left(\approx 10^{-6} \mathrm{mbar}\right)$ by using an oil diffusion pump (E306A, Edwards, UK). The source material $99.99 \%$ purity ZnSe powder (supplied by British Drug House, London, UK) was evaporated from a molybdenum boat and the substrate was placed at a distance of $10 \mathrm{~cm}$. The substrate temperature of the films varied from room temperature to $200^{\circ} \mathrm{C}$ keeping the film thickness fixed at $300 \mathrm{~nm}( \pm 10 \mathrm{~nm})$. The thickness and rate of evaporation of the films was measured in situ by the FTM 5 quartz crystal thickness monitor (Edwards, UK).

The X-ray diffraction (XRD) was used to investigate the structure of $\mathrm{ZnSe}$ thin films. The diffraction patterns were recorded using a Philips PW 3040 X'Pert PRO XRD system with $\mathrm{Cu}-\mathrm{K} \alpha$ radiation, operated at $40 \mathrm{kV}$ and $30 \mathrm{~mA}$, with angular range $15^{\circ} \leq 2 \theta$ $\leq 55^{\circ}$.

The thermal evaporation method was employed (Bhuiyan and Hasan 2006, 2007, Bhuiyan et al. 2008) by using an oil diffusion pump in vacuum to deposit ZnSe thin films. The variations of transmittance and specular absolute reflectance of the films with wavelength of light incident on them were measured using a dual beam UV-VIS-NIR recording spectrophotometer in the photon wavelength range between 300 and $2500 \mathrm{~nm}$.

\section{RESULTS AND DISCUSSION}

Fig. 1 shows the X-ray diffraction spectra of three ZnSe thin films having different substrate temperature deposited at $300 \mathrm{~nm}$ thickness. The spectra were obtained by scanning $2 \theta$ in the range between 15 and $55^{\circ}$. The presence of sharp peaks confirms the polycrystalline nature of the films. The diffraction spectrum has not been found for asdeposited film. It is observed that the films prepared at higher substrate temperature are polycrystalline in nature. The peak intensity increases with increasing substrate temperature. The diffraction spectra display the characteristics diffraction peaks of the cubic phase of $\mathrm{ZnSe}$. The peak at $2 \theta \approx 27.26^{\circ}$ is attributed to the X-ray reflection from 
the (111) planes of all the films. From the films deposited at higher substrate temperature, three prominent diffraction peaks were observed at $2 \theta$ values at $27.26,45.18$ and $53.42^{\circ}$ corresponding to (111), (220) and (311) planes, respectively which indicates random orientation of crystallites in these films (JCPDS card No. 05-0522).

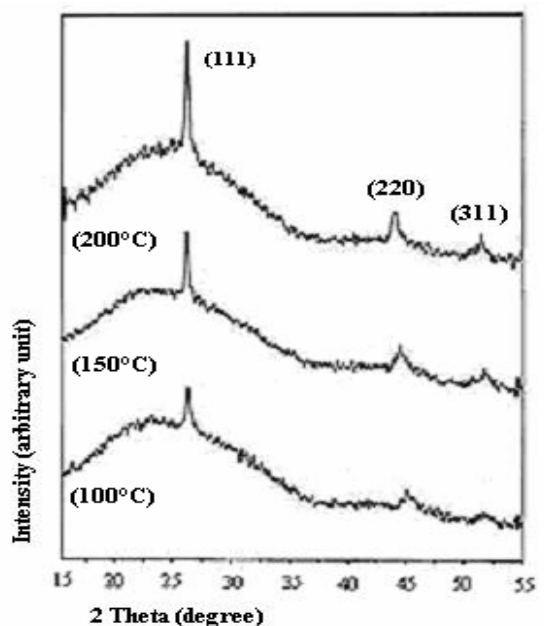

Fig. 1. X-ray diffraction spectra of ZnSe thin films having different substrate temperatures.

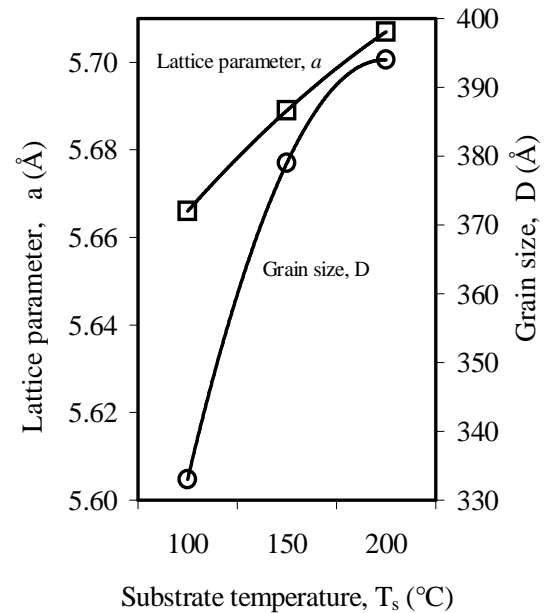

Fig. 2. Dependence of lattice parameters and grain size of $\mathrm{ZnSe}$ thin films having different substrate temperatures.

However, the intensities of the (220) and (311) peaks are extremely low in comparison with the (111) one. This indicates a preferential orientation of micro-crystallites with the (111) direction. The structural parameters are summarized in Table 1.

Table 1. Calculated values of structural parameters of $\mathrm{ZnSe}$ thin films having different substrate temperatures.

\begin{tabular}{cccccc}
\hline $\begin{array}{c}\text { Substrate } \\
\text { temperature } \\
\mathrm{T}_{\mathrm{s}}\left({ }^{\circ} \mathrm{C}\right)\end{array}$ & $\begin{array}{c}\text { Plane } \\
(h k l)\end{array}$ & $\begin{array}{c}\text { Lattice } \\
\text { parameter } \\
a\left(^{\prime}\right)\end{array}$ & $\begin{array}{c}\text { Grain size } \\
D\left(^{\prime}\right)\end{array}$ & $\begin{array}{c}\text { Strain } \\
\varepsilon \times 10^{-2} \\
\left(\mathrm{line}^{-2} / \mathrm{m}^{4}\right)\end{array}$ & $\begin{array}{c}\text { Dislocation } \\
\text { density } \\
\delta \times 10^{14}\left(\mathrm{line} / \mathrm{m}^{2}\right)\end{array}$ \\
\hline \multirow{2}{*}{100} & 111 & 5.666 & 333 & 6.215 & 9.018 \\
& 220 & & & & \\
150 & 111 & 5.689 & 379 & 5.462 & 6.962 \\
& 220 & & & & \\
& 311 & & 394 & 5.262 & 6.442 \\
& 111 & 5.707 & & & \\
\hline
\end{tabular}


Fig. 2 shows the variation of lattice parameter and grain size with different substrate temperatures. It is observed that both the lattice parameter and the grain size increases with the substrate temperature that confirms reasonably well to the literature (Chaliha et al. 2008). The concentration of lattice imperfections decreases with the increase in the substrate temperature due to the decrease in the internal micro-strain within the films and an increase in the grain size (El-Kadry et al. 1995). The increase in the grain size may be due to the coalescence of small crystals. The adatom mobility also increases as the substrate temperature increases which also results in the grain size and crystallinity of the films (Venkatachalam et al. 2006).

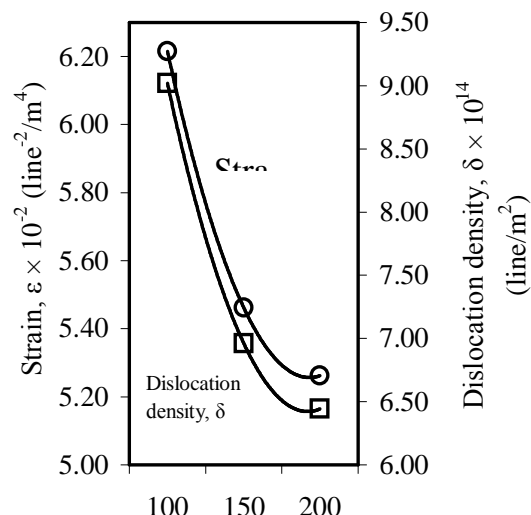

Substrate temperature Ts $\left({ }^{\circ} \mathrm{C}\right)$

Fig. 3. Dependence of dislocation density and strain of $\mathrm{ZnSe}$ thin films having different substrate temperatures.

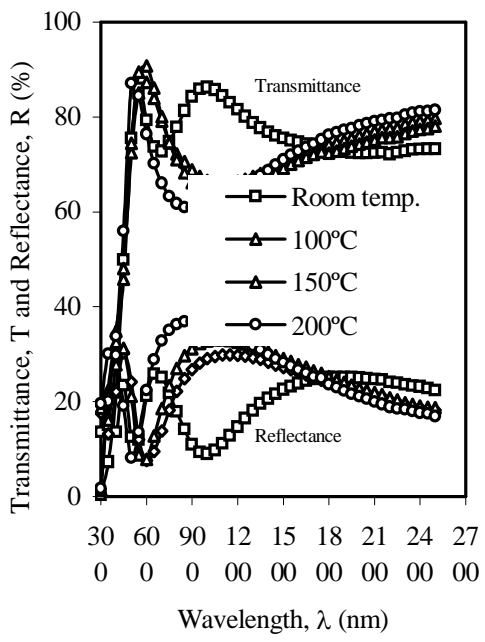

Fig. 4. Dependence of optical transmittance and reflectance on wavelength for $\mathrm{ZnSe}$ thin films having different substrate temperatures.

Fig. 3 shows the dislocation densities and strain decrease as the substrate temperature increases. Similar result for $\mathrm{ZnSe}$ thin films has been reported (Pal et al.1995). Since the dislocation density and strain are the manifestation of dislocation network in the films, the decrease in the strain and dislocation density indicates the formation of higher quality films at higher substrate temperatures. When the substrate temperature increases the line width narrows due to the increase in grain size.

The transmittance and reflectance spectra of $\mathrm{ZnSe}$ thin films deposited at different substrate temperatures having $300 \mathrm{~nm}$ thicknesses are shown in Fig. 4. The films demonstrate more than $80 \%$ transmittance at wavelengths longer than $550 \mathrm{~nm}$, which confirms reasonably well (Ennaoui et al. 2003). Transmittance decreases sharply to almost zero bellow $550 \mathrm{~nm}$ that is due to the strong absorbance of the films in this region. The films deposited at lower substrate temperatures exhibited slightly less transmittance in the visible region. 
The less transmittance observed at higher and lower substrate temperature could be due to the deviation of composition from stoichiometric structure of the films. The lower crystallinity of $\mathrm{ZnSe}$ layers deposited at such temperature may also be the reason for lower transmittance. The improved characteristics of the film at $200^{\circ} \mathrm{C}$ substrate temperature is also confirmed from absorption coefficient spectra, since it is observed that the spectrum for film at $200^{\circ} \mathrm{C}$ substrate temperature has more distinct absorption edge than those of other films. The reflectance spectra show the interference pattern with distinct peaks and valleys. It has also been found that the reflectance is small in the near infrared and visible region. The overall reflectance of the film increases with the increase in the substrate temperature.

The dependence of absorption coefficient on the photon energy for $\mathrm{ZnSe}$ thin films has been shown in fig. 5. These spectra reveal that the films show the significant absorption coefficient in the UV and visible regions. The values of absorption coefficient decrease with the increase in the substrate temperatures. This departure is caused owing to the presence of thermal lattice vibrations and imperfections. The increase in the substrate temperature produces a significant effect on the energy of the absorption edge. It shifts the absorption edge to the longer wavelength, which must be attributed to the growth of crystal grains and consequent decrease of quantum size effect (Kathalingam et al. 2007).

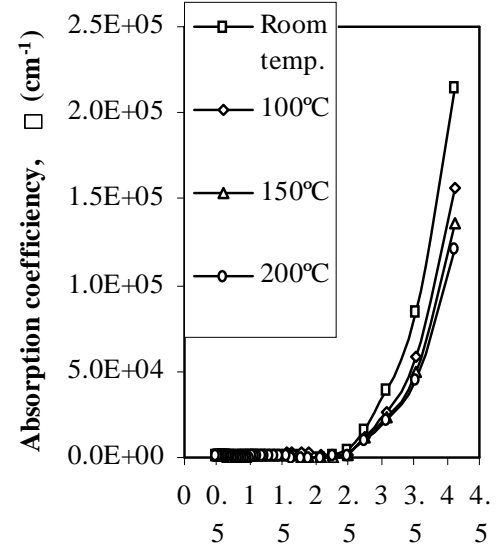

Photon energy, $h_{v}(e V)$

Fig. 5. Dependence of absorption coefficients on photon energy for $\mathrm{ZnSe}$ thin films having different substrate temperatures.

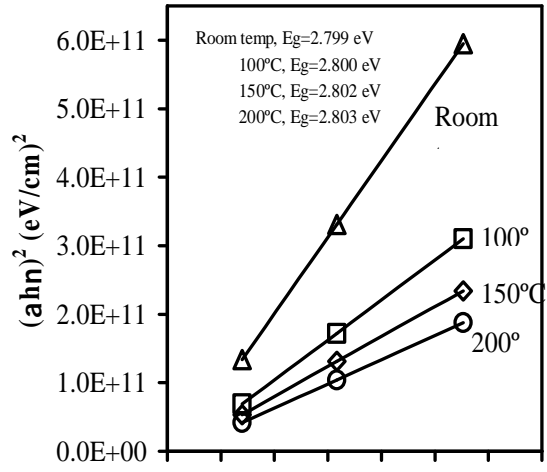

2.753 .003 .253 .503 .754 .004 .254 .50

Photon energy, hv (eV)

Fig. 6. Variation of $(\alpha h v)^{2}$ versus photon energy for $\mathrm{ZnSe}$ thin films deposited at different substrate temperatures.

The analysis of the absorption coefficient in the photon energy range $2.48 \leq h v \leq 4.133 \mathrm{eV}$ follows a relation for an allowed direct band gap energy (Patel and Kapale 1987), described by

$$
\alpha=\frac{A}{h v}\left[h v-E_{g}\right]^{1 / 2}
$$


where, $E_{g}$ is the band gap energy and $A$ is a parameter that depends on the probability of transition and the refractive index of the material. The band gap energies and the values of $A$ were found out from the plot of $(\alpha h v)^{2}$ versus $h v$ as shown in figure 6. Extrapolation of the linear portion of the curve to $(\alpha h v)^{2}=0$ gives the optical band gap and is found to be in the range from 2.799 to $2.803 \mathrm{eV}$ for different substrate temperatures which are in good agreement with the literature (Kumar et al. 2007). The calculated optical parameters are summarized in table 2 .

Table 2. Optical parameters of $\mathrm{ZnSe}$ thin films with varying substrate temperatures.

\begin{tabular}{ccc}
\hline Substrate temperature $\left({ }^{\circ} \mathrm{C}\right)$ & $\mathrm{Eg}(\mathrm{eV})$ & $\mathrm{A}\left(\mathrm{cm}^{-1} \mathrm{eV}^{1 / 2}\right)$ \\
\hline Room temp. & 2.799 & $6.68 \times 10^{5}$ \\
100 & 2.800 & $4.83 \times 10^{5}$ \\
150 & 2.802 & $4.19 \times 10^{5}$ \\
200 & 2.803 & $3.75 \times 10^{5}$ \\
\hline
\end{tabular}

The band gap energy (Eg) value is found to increase with the increase in the substrate temperature and the films are found to have direct allowed transition. The obtained Eg values are plotted as a function of substrate temperature in figure 7 . The band gap energy increases slightly from 2.799 to $2.803 \mathrm{eV}$ as the substrate temperature increases from room temperature to $200^{\circ} \mathrm{C}$. This might be related to the existence of high density of mid band gap levels that could give rise to the band tailing in polycrystalline materials.

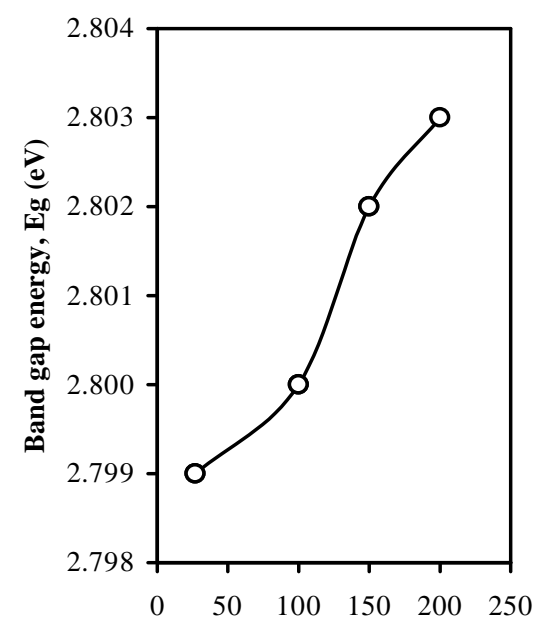

Substrate temperature, Ts $\left({ }^{\circ} \mathrm{C}\right)$

Fig. 7. Dependence of optical band gap energy with substrate temperature for $\mathrm{ZnSe}$ thin films.

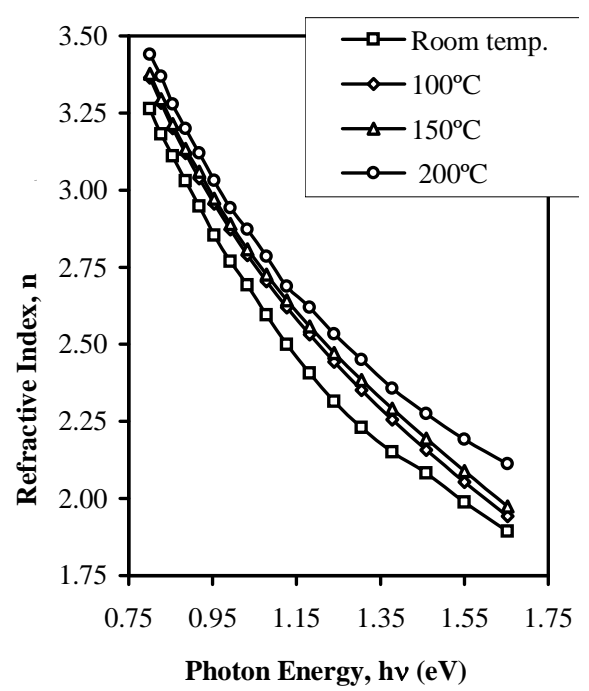

Fig. 8. Dependence of refractive index with photon energy for $\mathrm{ZnSe}$ thin films having different substrate temperatures. 
Fig. 8 shows the variations in the refractive index with photon energy for $\mathrm{ZnSe}$ thin Films having different substrate temperatures. It is observed from the figure that the refractive indices of the films decrease with increasing photon energy. It may also be observed that the values of refractive index deposited at room temperature were found to be less than those films deposed at higher substrate temperatures, which is in good agreement with the literature (Pal et al. 1995). Such a difference may be due to the larger grain size and lower strain in the films deposited at higher temperatures.

\section{CONCLUSIONS}

The XRD reveals that the films have been found to be polycrystalline in nature having cubic zinc blende structure. The lattice parameter and grain size increases with the increase of substrate temperature. However the internal strain and dislocation density decreases with the increase of substrate temperature. The optical behavior exhibits direct band gap energies 2.799 to $2.803 \mathrm{eV}$. It may be asserted that thin films of $\mathrm{ZnSe}$ having adequate quality for photovoltaic devices may be produced by vacuum evaporation method.

\section{ACKNOWLEDGEMENTS}

The authors are grateful to the authority of Atomic Energy Centre, Dhaka for providing the laboratory facilities. They are also thankful to Mr. Syed Ayubur Rahman, Mrs. Jahanara Parvin and Mr. Syed Ahmed for their assistance in preparing the samples.

\section{REFERENCES}

Bhuiyan, M.R.A. and S.M. Firoz Hasan. 2006. Optical absorption characteristics of polycrystalline $\mathrm{AgGaSe}_{2}$ thin films. J. Physics D: Applied Physics $39: 4935$.

Bhuiyan, M.R.A. and S.M. Firoz Hasan. 2007. Optical properties of polycrystalline $\mathrm{Ag}_{x} \mathrm{Ga}_{2-x} \mathrm{Se}_{2}(0.4 \leq x \leq 1.6)$ thin films. Solar Energy Materials Solar Cells 91 : 148.

Bhuiyan, M.R.A., S.M. Firoz Hasan and M.K. Rahman. 2008. Valence-band characterization of $\mathrm{AgGaSe}_{2}$ thin films. J. Physics D: Applied Physics 41 : 235108.

Chaliha, S., M.N. Borah, P.C. Sarmah and A. Rahman. 2008. Effect of substrate temperature on structural properties of thermally evaporated $\mathrm{ZnSe}$ thin films of different thickness. J. Physics Conference Series 114 : 012048.

Choudhury, M.G.M., M.R. Islam, M.M. Rahman, M.O. Hakim, M.K.R. Khan, K.J. Kao and G.R. Lai. 2004. Preparation and characterization of ZnSe:Al thin films. Acta Physica Slovaca 54: 4.

Chu, T.L., S.S. Chu, G. Chen, J. Britt, C. Ferekides and C.Q. Wu. 1992. Zinc selenide films and heterojunctions. J. Applied Physics $71: 3865$. 
El-Kadry, N., A. Ashour and S.A. Mahmoud. 1995. Structural dependence of d.c. electrical properties of physically deposited CdTe thin films. Thin Solid Films 269 : 112.

Ennaoui, A., W. Eisele, M. Lux-Steiner, T.P. Niesen and F. Karg. 2003. Highly efficient $\mathrm{Cu}(\mathrm{Ga}, \mathrm{In})(\mathrm{S}, \mathrm{Se})_{2}$ thin film solar cells with zinc-compound buffer layers. Thin Solid Films $\mathbf{4 3 1}$ $: 335$.

Guha, S., H. Munekata, F.K. LeGouse and L. Chang. 1992. Growth mode and dislocation distribution in the ZnSe/GaAs (100) system. Appl. Phys. Lett. $60: 3220$.

Guozhen, S., Di Chen, T. Kaibin and Q. Yitai. 2003. Characterization of ZnSe spheres via a rapid polyol process. J. Crystal Growth $257: 276$.

Huanyong, L. and J. Wanqi. 2003. Growth and characterizations of bulk ZnSe single crystal by chemical vapor transport. J. Crystal Growth $257: 110$.

Kale, R.B. and C.D. Lokhande. 2005. Influence of air annealing on the structural, morphological, optical and electrical properties of chemically deposited $\mathrm{ZnSe}$ thin films. Applied Surface Science 252 : 929.

Kathalingam, A., T. Mahalingam and C. Sanjeeviraja. 2007. Optical and structural study of electrodeposited zinc selenide thin films. Material Chemistry and Physics $106: 215$.

Kumaresan, R., M. Ichimura and E. Arai. 2002. Photochemical deposition of ZnSe polycrystalline thin films and their characterization. Thin Solid Films $414: 25$.

Kumar, V., K.L.A. Khan, G. Singh, T.P. Sharma, M. Hussain. 2007. ZnSe sintered films: Growth and characterization. Applied Surface Science 253 : 3543.

Pal, R., B. Maiti, S. Chaudhuri and A.K. Pal. 1995. ZnSe films: preparation and properties. Vacuum $46: 1255$.

Patel, S.M. and V.G. Kapale. 1987. Optical properties of $\mathrm{AgGaSe}_{2}$ thin films. Thin Solid Films 148 : 143 .

Perna, G., V. Capozzi, M.C. Plantamura, A. Minafra, P.F. Biagi, S. Orlando, V. Marotta and A. Giardini. 2002. Structural and optical properties of pulsed laser-deposited ZnSe films. Applied Surface Science 186 : 521.

Venkatachalam, S., D. Mangalaraj and S.K. Narayandassc. 2006. Influence of substrate temperature on the structural, optical and electrical properties of zinc selenide $(\mathrm{ZnSe})$ thin films. J. Physics D: Applied Physics 39 : 4777.

Yi, G.J., L. Radomsky and G.F. Neumark. 1994. Temperature dependence of luminescence in ZnSe and role of excitation transfer. J. Crystal Growth 138 : 208. 